\title{
Patiriella exigua: grazing by a starfish in an overgrazed intertidal system
}

\author{
A. C. Jackson ${ }^{1, *}$, R. J. Murphy ${ }^{2}$, A. J. Underwood ${ }^{2}$ \\ ${ }^{1}$ Environmental Research Institute, Castle Street, Thurso, Caithness KW14 7JD, UK \\ ${ }^{2}$ Centre for Research on Ecological Impacts of Coastal Cities, Marine Ecology Laboratories A11, University of Sydney, \\ New South Wales 2006, Australia
}

\begin{abstract}
Intertidal rocky shores in south-eastern Australia are dominated by a diverse assemblage of grazing invertebrates that feed on micro-algal biofilms. This resource is spatially variable and frequently over-grazed, causing strong inter- and intra-specific competition among grazers. Most studies on intertidal grazing are about gastropod molluscs. We observed, however, damaged patches in intertidal biofilms that appeared to be associated with the herbivorous asterinid starfish Patiriella exigua (Lamarck). In contrast with predatory starfish, there have been few ecological studies about herbivorous starfish, even though they are often abundant. We demonstrated that these patches were caused by grazing by this starfish. We then used field-based remote-sensing methods to demonstrate that amounts of chlorophyll were reduced inside grazing marks, quantified these changes and measured their longevity. In experiments, starfish could graze up to $60 \%$ of the epilithic micro-algae beneath their everted stomach during a single feeding event lasting on average 22 min. Over $5 \mathrm{~d}$, 2 caged starfish could remove nearly half of the available micro-algae from areas of $144 \mathrm{~cm}^{2}$. Changes to the amounts of chlorophyll in grazing marks were persistent, remaining visible on sandstone substrata for several weeks. Amounts of chlorophyll on grazed areas of substratum were significantly different from ungrazed areas up to $28 \mathrm{~d}$ after being grazed. Recovering areas were demonstrated to be bio-equivalent to ungrazed areas after a similar period. Thus, $P$. exigua can have a large effect on the temporal and spatial distribution of micro-algal food, with numerous possible consequences for intertidal assemblages. The ecological importance of herbivorous starfish may be greater than previously perceived.
\end{abstract}

KEY WORDS: Herbivore Intertidal $\cdot$ Echinoderm $\cdot$ Micro-algae $\cdot$ Spatial heterogeneity Chlorophyll Food

\section{INTRODUCTION}

Herbivory is widely recognised to have major effects on assemblages in terrestrial systems (e.g. ungulates: Hobbs 1996), open water (e.g. zooplankton: Lampert et al. 1986) and benthic habitats (e.g. crayfish: Creed 1994; echinoderms: Ogden et al. 1973, Laxton 1974, Sammarco et al. 1974; gastropods: Castenholz 1961, Nicotri 1977, Underwood 1980; and fish: Hixon \& Brostoff 1996).

On intertidal rocky shores and in many subtidal habitats, biofilms, consisting mainly of micro-algae (e.g. diatoms, cyanobacteria), are almost ubiquitous and are present even on apparently bare surfaces. Such biofilms are the main food of many small, diverse and abundant herbivores (Castenholz 1961, Nicotri 1977, Hawkins \& Hartnoll 1983). Grazing of these biofilms has several major influences on assemblagelevel patterns and processes.

Grazing changes spatial and temporal availability of resources, and heterogeneous environments often support greater numbers of species (Macarthur \& Macarthur 1961). Spatial heterogeneity can prevent predators from causing extinction of prey (Huffaker 1958, Hixon \& Menge 1991) and can stabilise fluctuations of populations (Murdoch 1977). Among competing 
species, persistence of poorer competitors may be dependent on physical heterogeneity in the distribution of resources (Fletcher \& Underwood 1987, Fransen et al. 2001). Heterogeneous dispersion of resources can also support greater densities of organisms (Doncaster 2001).

Settlement of the dispersive larvae of many sessile invertebrates (e.g. barnacles, oysters) is also influenced strongly by amounts and types of biofilm (Keough \& Raimondi 1995, 1996, Wieczorek \& Todd 1998). Thus, grazers altering the amounts, types and distributions of biofilms also affect patterns of settlement and subsequent assemblage structure.

Grazing on micro-algae also removes the early stages of development of macro-algae, preventing the growth of foliose macro-algae, which has numerous effects on the diverse assemblages in these habitats (reviewed in Hawkins \& Hartnoll 1983). Where the early microscopic phases of life history are not removed by grazing, fleshy, branched algae grow, smothering sessile animals, such as barnacles (Barnes \& Powell 1950, Dayton 1971) and other major occupiers of space. Such macroscopic algae cannot be eaten by many invertebrate marine grazers. These foliose, fleshy algae then occupy the space over which grazers of microscopic algae feed, reducing their food supply and causing grazers to move elsewhere or to lose weight and die from lack of food (Underwood \& Jernakoff 1981).

In contrast, where conditions do not favour rapid growth of micro-algae, densities of grazers can be large, resulting in widespread competition for food, resulting in reduced densities, decreased growth, reduced reproductive capacity, or death of grazers (Haven 1973, Underwood et al. 1983, Underwood 1984a, 1985). Consequently, in many intertidal and subtidal coastal habitats, grazing on biofilms is a major process influencing the local diversity of species, intensities of interactions and structure and composition of entire assemblages. Where densities of grazers are large or conditions are unfavourable for development of micro-algae, systems can often be overgrazed and food is inadequate.

Resources of micro-algae have been difficult to study, because sampling is generally laborious, imprecise, indirect and destructive (Underwood 1984b, Murphy \& Underwood 2006). Recently developed techniques using digital colour-infrared (CIR) imaging for non-destructive quantitative measurements of algae have improved such investigations (Murphy et al. 2006, Underwood \& Murphy 2008). Field spectrometry can also quantify amounts of different pigments in biofilms in situ, providing information on the composition of the algal assemblage (Murphy et al. 2005a). These techniques allow rapid, cost-effective information to be obtained non-destructively at the fine spatial scales relevant to benthic grazers.
Apart from a biofilm, many areas of rocky shore in south-eastern Australia are bare or covered by encrusting macro-algae. Competitive interactions among the grazing snails and limpets have been investigated experimentally, but observations in the field using CIR imagery suggested that grazing by the asterinid starfish Patiriella exigua (Lamarck) might also be important. These starfish are abundant in some areas, but little is known of their ecology or effects on other components of intertidal assemblages (Branch \& Branch 1980, Arrontes \& Underwood 1991, Stevenson 1992).

Some species of echinoderms have been studied experimentally to illuminate their effects on the structure of inter- or sub-tidal benthic assemblages. In particular, these include grazing urchins and predatory starfish. For example, Strongylocentrotus spp. can influence succession of benthic algae (Paine \& Vadas 1969) and affect the distribution and abundance of kelp (Lawrence 1975) and Lytechinus variegatus can regulate seagrass meadows (Valentine \& Heck 1991). Most adult starfish are predatory or omnivorous (Jangoux 1982). Some species have been well studied and can increase spatial heterogeneity either directly (Chesher 1969, Paine 1974) or indirectly (Duggins 1983). Juveniles (Sloan 1980) and adults of some species, particularly of Asterinidae, may, however, feed primarily on algal or microbial biofilms (Crump \& Emson 1978, Branch \& Branch 1980, Jangoux 1982).

Herbivorous starfish have, in contrast, received virtually no attention from ecologists, although Linckia laevigata, a subtidal starfish, eats coralline algae and can influence assemblages on coral reefs by slowing recolonisation by hard corals after disturbances (Laxton 1974). Yet, they may have important influences on the structure of intertidal assemblages, because their grazing contributes to the distribution and abundance of ecologically important biofilms, having numerous important indirect consequences as described above.

Patiriella exigua feed by everting their stomachs over the surface of the substratum, often on rock that is apparently bare or covered by encrusting algae. They can inhibit growth of macro-algae, but not as effectively as can other grazers, such as the limpet Cellana tramoserica (Sowerby) (Branch \& Branch 1980, Arrontes \& Underwood 1991). These limpets outcompete starfish, causing decreased growth of $P$. exigua (Branch \& Branch 1980, Arrontes \& Underwood 1991). Branch \& Branch (1980) argued that other grazers may be required in order to maintain a surface suitable for grazing by the starfish, but Arrontes \& Underwood (1991) demonstrated that this was not the case, because $P$. exigua can exploit surfaces with variable covers of algae and can use substrata unavailable to other grazers. 
The experiments described here were to investigate grazing by Patiriella exigua, in particular their capacity to influence availability of resources to other grazers and any consequences to the overall ecology of assemblages on rocky shores. Well-defined circular or pentagonal patches were observed in micro-algal biofilms growing in intertidal rockpools; these appeared to be the result of greatly reduced densities of micro-algae. The patches seemed to persist for several days or even weeks, and their sizes and shapes suggested that they were associated with $P$. exigua. Patches of cyanobacteria similar in size and shape were also observed nearby. To understand the processes causing and consequences of these patches, we tested whether they were caused by grazing of $P$. exigua, predicting that patches similar in size and shape to the starfish would appear after they had fed in experimental areas. Then, to test models about the effects of grazing by $P$. exigua, we measured amounts of micro-algae removed where starfish were grazing.

To understand foraging by Patiriella exigua, we estimated the amounts of algae removed in a single feeding event and the time required to do this. We therefore measured the absolute and relative reductions of micro-algae in individual feeding marks and recorded the duration of feeding events. Foraging by starfish may target particular types of micro-algae or may differentially affect the subsequent survival or growth of different algae. If grazing by starfish has important influences on the spatial distribution of epilithic micro-algae, its effects should persist through time after grazing has ceased. We compared changes in amounts of micro-algae on grazed or ungrazed areas through time to measure the persistence of grazing marks and to test the prediction that grazed areas would 'recover' to be like ungrazed areas over several weeks (a time-frame appropriate for the re-growth of micro-algae). We also tested the prediction that grazing by $P$. exigua would result in subsequent development of different biofilms and whether these were the causes of the observed patches of cyanobacteria that seemed to be of similar size and shape to patches made by grazing starfish. To test for differential subsequent effects of grazing, we also measured compositions of assemblages of micro-algae in grazed or ungrazed areas (as in Murphy et al. 2005a).

\section{MATERIALS AND METHODS}

Grazing in the laboratory. From October to November 2007, biofilms dominated by diatoms grew on sandstone slabs $(200 \times 200 \mathrm{~mm})$ and on glass plates $(200 \times 200 \mathrm{~mm})$ in a recycled seawater system in the laboratory. To test the hypothesis that pentagonal marks observed in the field were due to grazing by starfish, a sandstone slab was placed in each of 6 tanks, 3 with 2 Patiriella exigua and 3 without. Grazing by $P$. exigua on sandstone slabs in the laboratory was recorded using digital video, and slabs were examined for marks the next day. The duration of an individual feeding event was calculated as the time (min) that a starfish was pentagonal rather than star-shaped (see 'Results') between 2 periods of movement.

Grazing in the field. Experiments were done on a rocky shore at Cape Banks Scientific Marine Research

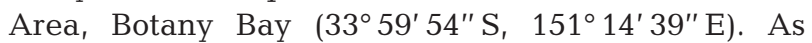
described in detail elsewhere (e.g. Underwood 1981), the low intertidal areas of these shores often have macro-algal turfs, whereas the mid- and upper tidal have few foliose algae and large, diverse populations of grazers. In these areas, much of the sandstone substratum is either apparently bare (biofilm only) or covered with encrusting macro-algae (typically Hildenbrandia rubra (Somm.) Menegh. or Ralfsia verrucosa (Aresch. J.Ag.). Patiriella exigua are common on these shores and have been recorded at densities of up to $150 \mathrm{~m}^{-2}$ (Branch \& Branch 1980). P. exigua appeared to be most abundant in the many rockpools found on these wave-cut platforms, but were also present in cryptic habitats such as crevices, under macro-algae and under boulders. Densities of starfish were sampled in August 2008 in several habitats, e.g. by counting all individuals in small rockpools $\left(<0.04 \mathrm{~m}^{2}\right)$ or by sampling with quadrats $(270 \times$ $270 \mathrm{~mm}$ ) in larger pools, under boulders, or on open surfaces. Of the mid-low intertidal area of these shores, 20 to $40 \%$ was estimated to be rockpools (A. C. Jackson unpubl. data).

Biofilms grew during early summer (October to December) of 2007 , on the surface of 12 sandstone slabs $(200 \times 200 \times 30 \mathrm{~mm})$ secured with bolts at the bottom of shallow intertidal rockpools on the upper shore ( $1.4 \mathrm{~m}$ above zero tide level) at Cape Banks. The intertidal pools contained no Patiriella exigua, but other grazers, including Nerita atramentosa Reeve, Bembicium nanum (Lamarck) and Littorina unifasciata Gray, were numerous and prevented growth of macroalgae. After 6 wk (during which micro-algal assemblages developed), galvanised wire-mesh cages $(120 \times$ $120 \times 40 \mathrm{~mm}, 5 \mathrm{~mm}$ mesh) lined with $1 \mathrm{~mm}$ plastic flymesh were secured over the slabs to prevent any grazers from moving in or out. Two $P$. exigua were placed in each of 6 randomly chosen cages (grazed). This density $\left(138 \mathrm{~m}^{-2}\right)$ is within the range of densities observed in rockpools on rocky shores in this area (Branch \& Branch 1980, Arrontes \& Underwood 1991, present study). $P$. exigua were allowed to graze for $5 \mathrm{~d}$, after which the cages and starfish were removed. Development of micro-algae was allowed to continue 
for a further $4 \mathrm{wk}$. Experiments in the laboratory suggested that this time scale was appropriate and would provide sufficient time for grazing to occur, yet not be so long that all algae would be removed. The mean diameter $(\mathrm{mm})$ of $P$. exigua when feeding was estimated from 50 randomly selected starfish.

Colour-infrared imagery. Each sandstone slab was photographed immediately prior to the start of the experiment (Day 0), after Patiriella exigua had been allowed to graze for a period of $5 \mathrm{~d}$ (Day 5) and, on 2 subsequent occasions, after $P$. exigua had been removed (Days 15 and 33). Images were obtained using a 3-CCD digital CIR camera (Geospatial Systems Inc.) fitted with a Sigma $14 \mathrm{~mm}$ f/2.8 ES/HSM super wideangle lens. The camera records reflected light at nearinfrared (NIR; 758 to $833 \mathrm{~nm}$ ), red (645 to $689 \mathrm{~nm}$ ) and green (525 to $575 \mathrm{~nm}$ ) wavelengths recorded as separate images. Algal cells scatter light in the NIR, but chlorophyll absorbs light in the red. A ratio of NIR and red wavelengths, therefore, quantifies the amount of absorption by chlorophyll and is an accurate index of the amounts of chlorophyll present on the rock surface (Murphy et al. 2006). The brightness of the images was controlled by adjusting the interval of time (integration time) over which the image was recorded. CIR images $1392 \times 1039$ pixels in size were obtained under natural sunlight from a height of $1 \mathrm{~m}$, each pixel in the image measuring an area of $0.35 \times 0.35 \mathrm{~mm}$. Slabs were removed from the rockpools to take photographs (and for spectrometry - see subsection 'Field spectrometry') and replaced immediately.

NIR and red layers of the images were calibrated to remove variations caused by changing solar illumination and integration times, as in Murphy et al. (2006). Amounts of chlorophyll were calculated for each pixel in the NIR/red image using Eq. (3) in Murphy et al. (2006).

Removal of algae. To test the hypothesis that starfish remove algae, we compared amounts of chlorophyll on grazed or ungrazed slabs on Days 0 and 5, using the mean amount of chlorophyll calculated from 10 regions of interest (ROI; each $20 \times 20$ pixels) placed randomly on each slab.

Predicting growth of algae. The amount of algae varied from slab to slab. To calculate how much was removed by grazers, we predicted how much would have been present in the absence of grazing, assuming linearly increasing biomass through time. The amount grazed from each slab could then be estimated as the predicted amount if ungrazed, minus what remained after grazing had ceased.

Predicted ungrazed amounts were calculated using the amounts of chlorophyll on Day 5 on each of the ungrazed slabs separately regressed on the amounts present at the start (Day 0) on that slab. On each ungrazed slab, the entire caged area was divided into $20 \times 20$ blocks (each of $18 \times 18$ pixels) and used for these regressions, which were forced through the origins. To match these blocks for Day 5, images were registered to the Day 0 images, $<1$ pixel, using interactive image analysis to identify common 'tie-points' (e.g. mineral grains, morphology of the slab surface) between images acquired at different times. A polynomial warping procedure was then used to register the images. Then, for each slab, the amounts of chlorophyll on Day 5 were subtracted from the predicted amounts to give the mean amount removed from the whole caged area of the slab.

Individual feeding events. Grazing by starfish was more extensive than expected between Days 0 and 5 . On one grazed slab, virtually no space was ungrazed; on others, there were a few marks that did not overlap. To measure how much chlorophyll was removed per feeding event, chlorophyll was measured over all the pixels in each of 7 isolated and clearly defined feeding marks on each of 5 slabs and subtracted from the amounts predicted for Day 5 for the same pixels.

Persistence of grazing marks. Persistence of grazing marks was measured by comparing amounts of chlorophyll in 10 randomly selected ROIs for each grazed or ungrazed slab (see subsection 'Removal of algae'), from Days 5, 15 and 33. Persistence of individual grazing marks was assessed using a bio-equivalence comparison, at each time, of the amount of chlorophyll inside grazing marks with the amounts immediately outside the same area. Mean amounts of chlorophyll were estimated from 2 transects across each of 12 grazing marks (taken from 4 grazed slabs) at each time. Extensive grazing prevented equal numbers of transects being taken from all grazed slabs. Within the grazing mark 15 to 20 pixels were measured, and a similar number was measured immediately outside the mark (half from one end of the transect, half from the other). Registration of the images meant that each mark was in the same place $( \pm 1$ pixel $)$ at each time, and the clearly defined marks on Day 5 were used to locate the positions of the transects for Days 0, 15 and 33. Because amounts of algae varied across and among slabs, the amounts of chlorophyll at Days 5, 15 and 33 were standardised by dividing by the initial amount (Day 0). For each date sampled (i.e. Days 5, 15 and 33, which are 0, 10 and $28 \mathrm{~d}$ after grazing ended, respectively), the amount of chlorophyll in the grazed pixels was compared to the ungrazed pixels in each mark. We considered that grazed areas had recovered (i.e. matched those in ungrazed areas) when the mean ratio of chlorophyll in grazed to ungrazed pixels was significantly greater than the lower boundary and significantly less than the upper boundary of an equivalence interval defined a priori (i.e. the 2 one- 
sided test procedures; Schuirmann 1987). The equivalence interval was defined as a $30 \%$ change in the amount of ungrazed chlorophyll, because changes of this magnitude have important consequences for intertidal grazers (Underwood 1985).

Field spectrometry. To test the hypothesis that grazing by Patiriella exigua would alter the composition of micro-algal assemblages, field spectrometry (Analytical Spectral Devices, FieldSpec Pro) was used to measure the relative abundance of absorption by pigments between 400 and $750 \mathrm{~nm}$ (Murphy et al. 2005a,b) on Days 0, 15 and 33. Four replicate spectra in random positions were acquired from each slab, each spectrum measuring reflected light from an area of slab $\sim 4 \mathrm{~cm}$ in diameter. Where possible, we also collected spectra from grazed and, separately, ungrazed areas of grazed slabs on Day 33. Spectra were standardised for amounts of reflectance by dividing each spectrum by the values from a $99 \%$ reflective spectralon reference panel taken immediately before each reading.

Reflectance spectra of micro-algal assemblages contain absorption values due to different photosynthetic pigments. Derivative analysis of the spectra enhances subtle absorption features and removes effects caused by differences in brightness of the substratum and gross variations in brightness caused by calibration errors. Fourth-order derivatives were calculated from absorbance spectra [log (1/reflectance)] by the combined differentiation and smoothing method of Savitzky \& Golay (1964), using a smoothing window of $24 \mathrm{~nm}$. The resulting derivative spectra show pigment absorption values as 'peaks' above a zero baseline. By comparing the wavelength position and width of each peak to the published wavelength positions of known pigments in vivo, it is possible to identify and quantify the pigments present. The absorption values of 10 different pigments were identified and standardised to correct for differences among replicates in the total amount of pigment, by dividing by size of the peak for chlorophyll a for each replicate.

\section{RESULTS}

\section{Grazing in the laboratory}

Overnight, slabs with starfish developed visible pentagonal marks darker than the background biofilm; no such marks appeared on slabs without Patiriella exigua. When moving around, $P$. exigua adopted a star shape, with clearly defined arms (Fig. 1a). When feeding, the cardiac stomach was everted, the starfish became much more pentagonal, and it was more difficult to distinguish the arms from the central disk (Fig. 1b). This change in shape could be used in the laboratory or field to determine, from an aboral view, whether or not a starfish was feeding. The mean $( \pm \mathrm{SE})$ duration of 72 feeding events by 4 starfish on sandstone slabs in the laboratory was $22 \pm 3 \mathrm{~min}$, and the mean interval between feeding events was $7 \pm 1 \mathrm{~min}$.

Starfish feeding on glass plates were observed to evert the cardiac stomach through the mouth, expanding it until it reached or even exceeded the margin of the body (Fig. 1b, dotted white outline). The shape assumed by the stomach was not exactly pentagonal, because there was a notch at the edge of the stomach near the tip of each ambulacral groove, allowing a few tube feet to remain in contact with the substratum. The patches evident in biofilm growing on the sandstone were very similar in size and shape, including the
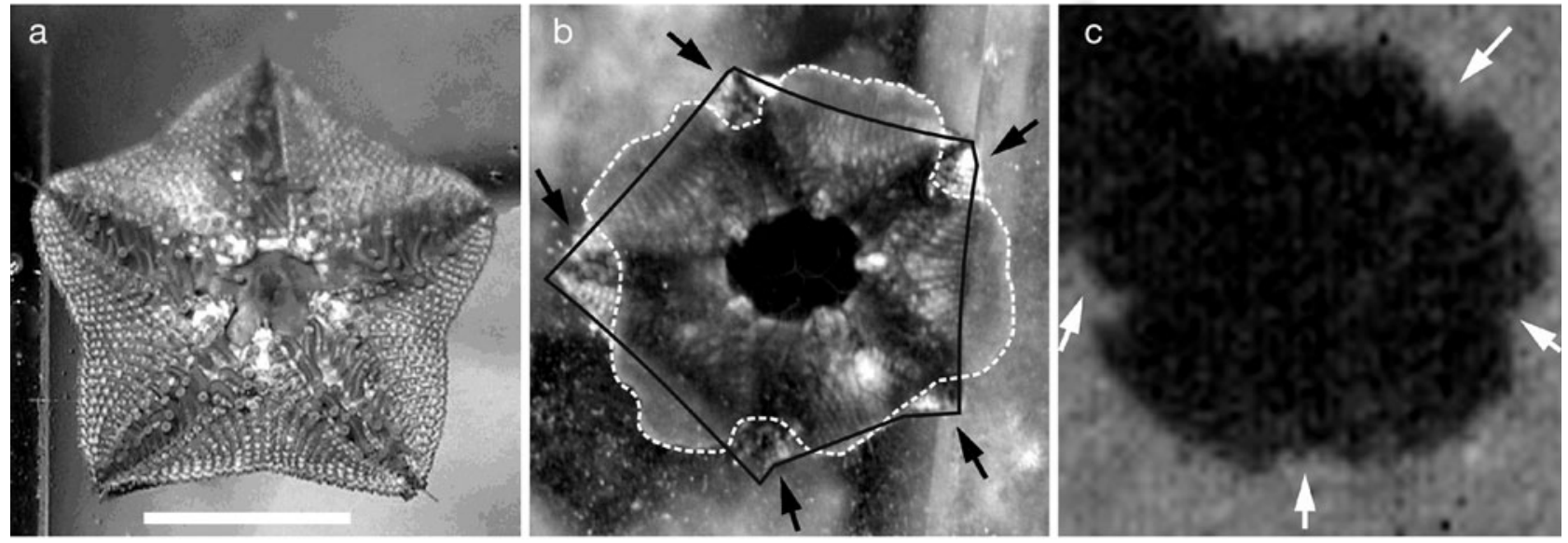

Fig. 1. Patiriella exigua. Oral view: (a) when mobile, with stomach retracted and the arms forming a star (white scale bar: 10 mm) and (b) while feeding, with stomach extruded (black outline shows the body; dotted white line indicates the extent of the fully extruded stomach). Notches in the shape of the stomach (black arrows) allow tube feet to remain in contact with the substratum.

(c) An individual grazing mark; notches in similar positions to the extruded stomach (as in b) are shown (white arrows) 
presence of 5 notches (Fig. 1c). This demonstrated conclusively that the marks observed in the biofilm and in the field were the result of grazing by Patiriella exigua.

\section{Grazing in the field}

Densities of starfish

Densities of Patiriella exigua were greatest in rockpools, particularly those $<200 \mathrm{~mm}$ in diameter in lowor mid-shore areas ( 0.7 to 1.0 or 1.0 to $1.2 \mathrm{~m}$ above zero tide, respectively), and were also great under boulders in large rockpools, reaching as many as several 100 per square metre (Table 1). No starfish were seen on open rock or in any habitat on the upper shore $(>1.4 \mathrm{~m}$ above zero tide).

\section{Reductions of chlorophyll}

There was great variation among slabs in the initial amounts of biofilm (Table 2). Chlorophyll a increased on all 6 ungrazed slabs between Days 0 and 5, but decreased on 5 of 6 grazed slabs, and the interaction between treatment and time was significant (Table 2). On Day 1, amounts of chlorophyll did not differ between treatments, but, on Day 5, there was significantly more chlorophyll on ungrazed than on grazed slabs (mean $\pm \mathrm{SE}: 2.2 \pm 0.1$ and $0.8 \pm 0.06 \mu \mathrm{g} \mathrm{cm}^{-2}$, respectively; SNK, p < 0.01).

The regressions of increases in the amounts of chlorophyll between Days 0 and 5 differed significantly among the ungrazed slabs (test for heterogene-

Table 1. Patiriella exigua. Densities $\left(\mathrm{m}^{-2}\right)$ in various habitats on rocky intertidal shores at Cape Banks. Small rockpools: $<0.04 \mathrm{~m}^{2}$; large rockpools and boulders: $>0.08 \mathrm{~m}^{2}$

\begin{tabular}{|c|c|c|c|c|c|}
\hline Habitat & Size & Algae & Mean & $\mathrm{SE}$ & $\mathrm{n}$ \\
\hline \multicolumn{6}{|l|}{ Mid-shore } \\
\hline Open rock & - & Bare/encrusting & 0 & 0 & 40 \\
\hline Rockpool & Small & Bare/encrusting & 245 & 32 & 65 \\
\hline Rockpool & Large & Bare/encrusting & 40 & 5 & 75 \\
\hline Rockpool & Large & Foliose & 23 & 5 & 25 \\
\hline \multicolumn{6}{|l|}{ Low-shore } \\
\hline Open rock & - & Bare/encrusting & 0 & 0 & 40 \\
\hline Rockpool & Small & Bare/encrusting & 127 & 33 & 10 \\
\hline Rockpool & Large & Bare/encrusting & 28 & 12 & 12 \\
\hline Rockpool & Large & Foliose & 30 & 5 & 20 \\
\hline \multicolumn{6}{|c|}{ Under boulders } \\
\hline Open rock & - & - & 47 & 8 & 25 \\
\hline Rockpool & - & - & 81 & 21 & 15 \\
\hline
\end{tabular}

ity of slopes, $\left.F_{4,2378}=89951, \mathrm{p}<0.001\right)$. This was partly because large sample sizes $(n=400)$ can detect very small differences, but made it necessary to choose the appropriate slope for predicting the ungrazed amounts of chlorophyll on grazed slabs. One grazed slab had readily identifiable areas that had not been grazed (Fig. 2b). Amounts of chlorophyll measured in these areas were compared with the amounts predicted using the various regressions. The mean slope of the regressions from the 6 ungrazed slabs was 1.52, which gave a close fit between predicted and observed amounts $\left(r^{2}=0.88, n=180\right)$ and was therefore used to predict ungrazed amounts of chlorophyll for each grazed slab.

How much chlorophyll was eaten?

Amounts of chlorophyll on one slab are shown before and after grazing (Fig. 2a,b). Some areas were not grazed, so frequency distributions of amounts of chlorophyll per pixel were bimodal, reflecting well the visible appearance of grazed patches on slabs (Fig. 2c). The right-hand peak (ungrazed areas) of this distribution was centred on the same mean as the predicted amounts of chlorophyll per pixel for ungrazed areas. The difference between this peak and the original single mode of the amounts of chlorophyll before grazing started (Day 0) indicates the growth of chlorophyll on ungrazed areas. The left-hand peak was centred on the mean amount of chlorophyll in grazed areas. The difference between the 2 peaks estimates the amount of chlorophyll removed by grazing (Fig. 2c). The mean $( \pm \mathrm{SE}, \mathrm{n}=6$ cages) total predicted (if ungrazed) and actual amounts of chlorophyll in grazed areas on grazed slabs on Day 5 were $237 \pm 31$ and $123 \pm 22 \mu \mathrm{g}$ cage $^{-1}$, respectively. The amount of chlorophyll grazed from each cage was, thus, $114 \pm 26 \mu$, i.e. $47 \pm 6 \%$ of the amount available.

The mean $( \pm \mathrm{SE})$ amount of chlorophyll removed per feeding event was $0.96 \pm$ $0.07 \mu \mathrm{g} \mathrm{cm}^{-2}$ ( $\mathrm{n}=35$ feeding events), which was, on average, $60 \pm 5 \%$ of that available under the everted stomach of a starfish prior to grazing. The mean area of substratum grazed during each feeding event was $2.0 \mathrm{~cm}^{2}$ (mean diameter of Patiriella exigua of $1.6 \mathrm{~cm}$ when grazing, assuming the extruded stomach was circular), and thus each feeding event by an average starfish removed $1.92 \mu \mathrm{g}$ of chlorophyll. The total amount of chlorophyll grazed could have been removed by 60 feeding events, 
Table 2. Analysis of amounts of chlorophyll $\left(\mu \mathrm{g} \mathrm{cm}^{-2}\right)$ on experimental slabs. Treatment (fixed: grazed or ungrazed), time (fixed; Day 0 versus Day 5 and Day 5 versus Day 15 versus Day 33) and slab (random: 6 levels nested in treatment); $\mathrm{n}=10$ replicate regions of interest on each slab

\begin{tabular}{|c|c|c|c|c|c|c|c|c|}
\hline \multirow[b]{2}{*}{ Source of variation } & \multicolumn{4}{|c|}{ Day 0 vs. Day 5} & \multicolumn{4}{|c|}{ Day 5 vs. Day 15 vs. Day 33} \\
\hline & df & MS & $F$ & $\mathrm{p}$ & df & MS & $F$ & $\mathrm{p}$ \\
\hline Treatment & 1 & 43.3 & 5.3 & $>0.05$ & 1 & 45.4 & 5.4 & $<0.05$ \\
\hline Time & 1 & 4.4 & 2.8 & $>0.1$ & 2 & 7.1 & 3.9 & $<0.05$ \\
\hline Slab(Treatment) & 10 & 8.3 & 115.0 & $<0.001$ & 10 & 8.5 & 132.7 & $<0.001$ \\
\hline Treatment $\times$ Time & 1 & 17.3 & 11.0 & $<0.01$ & 2 & 11.2 & 6.2 & $<0.01$ \\
\hline Time $\times$ Slab $($ Treatment) & 10 & 1.6 & 22.0 & $<0.001$ & 20 & 1.8 & 28.5 & $<0.001$ \\
\hline Residual & 216 & 0.1 & & & 324 & 0.1 & & \\
\hline
\end{tabular}

which, given the mean duration of and interval between feeding events in the laboratory (see 'Grazing in the laboratory'), could easily be achieved by 2 starfish over $5 \mathrm{~d}$.

Persistence of grazing marks

Analysis of the amounts of chlorophyll on the slabs on Days 5, 15 and 33 showed complex interactions between the factors time and slabs (Table 2). On grazed slabs, the amounts of chlorophyll increased after the starfish were removed. In contrast, the amounts of chlorophyll on ungrazed slabs decreased between Days 5 and 33. This was probably because the cages (which provided shade and enhanced growth of algae) were removed on Day 5. Amounts of chlorophyll were significantly greater on ungrazed than on grazed slabs by Day 5 (SNK tests of the significant interaction treatment $\times$ time; $p<0.01)$ and on Day $15(\mathrm{p}<0.05)$, but not different on Day 33 ( $p>0.05$ ). By Day 33, i.e. 28 d after grazing ended, the ratio of chlorophyll in grazed to un- grazed pixels was significantly $>0.7$ (1-tailed $t_{11 \mathrm{df}}=$ $3.76, \mathrm{p}<0.01$ ) and significantly $<1.3$-times the ungrazed pixels (1-tailed $t_{11 \mathrm{df}}=9.34, \mathrm{p}<0.001$ ), so grazed pixels were considered to be recovered to a condition equivalent to ungrazed pixels (Fig. 3).

\section{Field spectrometry}

The compositions and relative magnitudes of the peaks of absorbance for individual pigments were analysed as multivariate data, but there were no differences between either grazed or ungrazed slabs at any time, nor between grazed or ungrazed areas of grazed slabs at the end of the experiment; no data or analyses are presented.

\section{DISCUSSION}

The starfish Patiriella exigua can graze large amounts of epilithic micro-algae on intertidal rocky
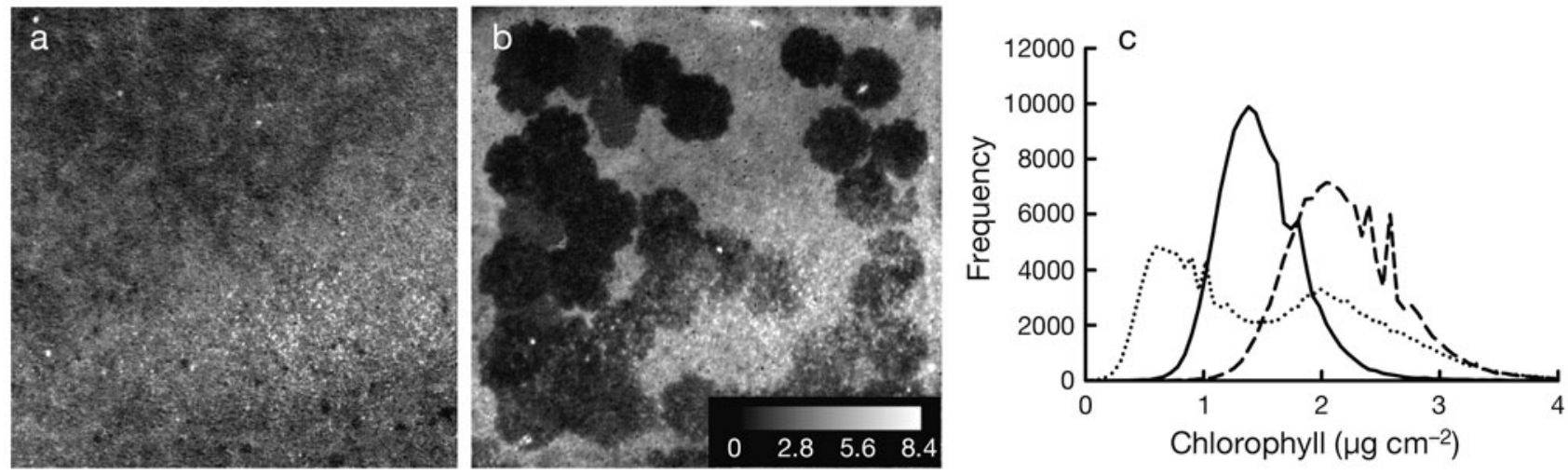

Fig. 2. Amounts of chlorophyll inside a cage: (a) on Day 0 before grazing and (b) after 5 d of grazing by 2 Patiriella exigua. The pixel values (brightness) are scaled between 0 and 255; the brighter the pixel, the greater the amount of chlorophyll (shown in the grey-scale index in $\mu \mathrm{g} \mathrm{cm}^{-2}$ ). Light grey areas: ungrazed; near-black pentagonal areas: the feeding marks of $P$. exigua; bright white speckles to lower right: sporelings of macro-algae. (c) Frequency distributions for the amounts of chlorophyll $\left(\mu \mathrm{g} \mathrm{cm}^{-2}\right)$ per pixel for 135 000 pixels for the caged area of the same grazed slab before grazing on Day 0 (continuous line), predicted ungrazed amounts for Day 5 (dashed line) and actual grazed amounts on Day 5 (dotted line) 

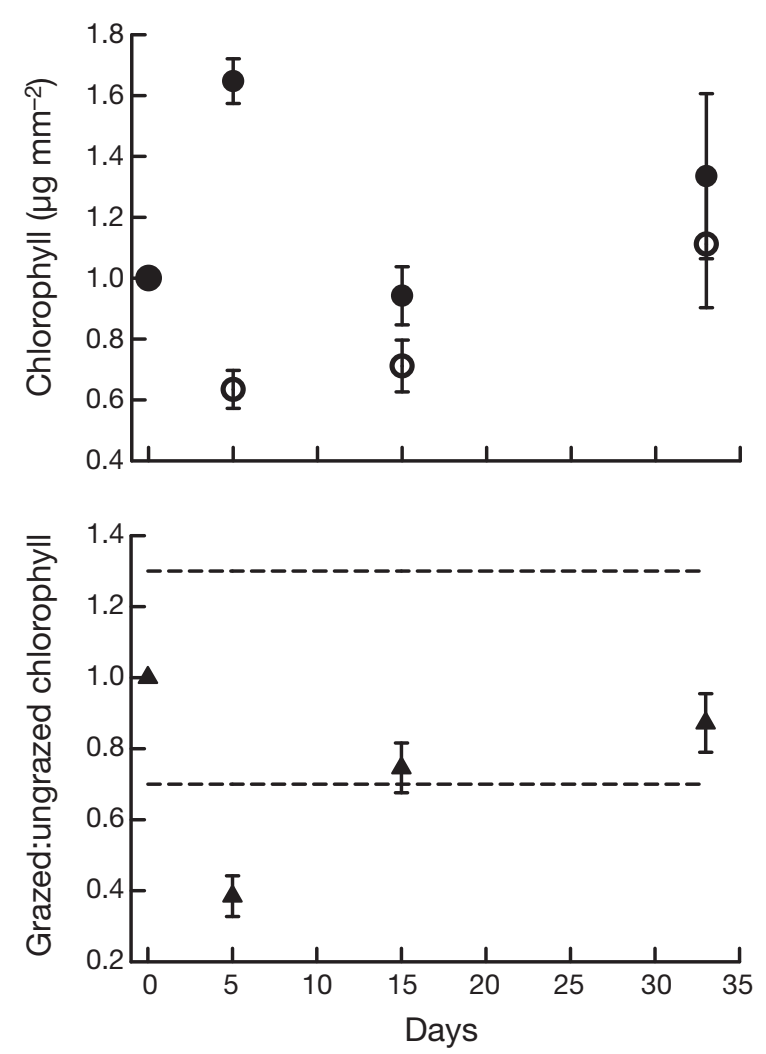

Fig. 3. (a) Mean $( \pm S E ; n=12)$ amounts of chlorophyll on grazed (O) or ungrazed $(\mathbf{)})$ sections of transects across feeding marks. (b) Mean ( $\pm 95 \%$ confidence interval; $\mathrm{n}=12$ ) ratio between chlorophyll on grazed and ungrazed pixels in these transects $(\mathbf{\Delta})$, with equivalence intervals reflecting 30\% increases or decreases in ungrazed chlorophyll (dashed lines) at each time. There was no variability or difference between grazed or ungrazed pixels on Day 0 , because the amounts of chlorophyll on all transects were scaled to the amount present on that transect on Day 0. Equivalence to ungrazed areas was reached by Day 33 (28 d after grazing ceased)

shores, which contributes to temporal and spatial heterogeneity of micro-algal biofilm, thus potentially influencing assemblage-level processes such as recruitment of sessile species, competition among grazers and growth of macro-algae. The ecological importance of this grazer may be greater than previously perceived.

Damage or 'feeding scars' caused by predatory starfish have been observed on sponges and anthozoans (Jangoux 1982, Laxton 1974), but, despite an extensive search of the literature, we found few studies about the ecology of grazing starfish (e.g. Laxton 1974) and virtually nothing about their effects on algae. This is in strong contrast to the numerous studies on effects of other grazers on algae (e.g. Castenholz 1961, Nicotri 1977, Underwood 1984c, Johnson et al. 1997, Murphy \& Underwood 2006). In particular, gastropods (Hawkins \& Hartnoll 1983, Stafford \& Davies 2005) and urchins (Ogden et al. 1973, Fletcher 1987) can con- tribute strongly to the spatial heterogeneity of algae by forming grazing halos around places where they shelter.

Pentagonal marks observed in natural micro-algal biofilms were unambiguously attributable to the feeding behaviour of Patiriella exigua (Fig. 1), and the marks corresponded with decreases in amounts of chlorophyll (Fig. 2). Over 5 d, 2 starfish grazed almost half the chlorophyll in experimental cages covering $144 \mathrm{~cm}^{2}$, and, during a single feeding event, a starfish could remove $60 \%$ of the chlorophyll beneath its everted stomach.

The amounts of chlorophyll in micro-algal biofilms at mid-tidal heights on rocky shores around Sydney are often between 1 and $2 \mu \mathrm{g} \mathrm{cm}{ }^{-2}$ (authors' unpubl. data). In rockpools, amounts of chlorophyll are likely to be greater, but are more difficult to measure because of the overlying water. Predicted ungrazed amounts of chlorophyll on slabs in rockpools in our study were in this range. Although there were no Patiriella exigua on open surfaces during low tide, the very large densities in pools, which often represented a considerable proportion of the shore, meant that overall mean densities could still be quite large. Many intertidal grazers feed only during high tide, but, for $P$. exigua in rockpools, feeding is possible during all states of tide. During high tide, $P$. exigua are, however, not restricted to rockpools and will feed elsewhere. Feeding 'scars' were regularly seen on surfaces that dried during low tide. If durations of feeding events are similar in the field and in the laboratory, $1.92 \mu \mathrm{g}$ of chlorophyll could be removed by a single, average-sized $\left(2 \mathrm{~cm}^{2}\right)$ starfish in about 20 min (see 'Grazing in the laboratory'). At the scale of small pools, natural densities of $P$. exigua can reach $150 \mathrm{~m}^{-2}$ (Branch \& Branch 1980, Arrontes \& Underwood 1991) or $>1000 \mathrm{~m}^{-2}$ (present study), and, although mean densities are considerably less (between 0 and $245 \mathrm{~m}^{-2}$ depending on habitat; Table 1), the numbers of starfish on the shore and the amounts of micro-algae removed are large. For example, during high tide, using a conservative estimate of overall density of $25 \mathrm{~m}^{-2}$, assuming that $90 \%$ of starfish feed at any one time (as shown by Arrontes \& Underwood [1991] in rockpools), each removing on average $1.92 \mu \mathrm{g}$ of chlorophyll, $43 \mu \mathrm{g}$ would be removed from $1 \mathrm{~m}^{2}$ of shore in $20 \mathrm{~min}(25 \times 0.9 \times 1.92=43 \mu \mathrm{g}$ chlorophyll $\mathrm{m}^{-2}$ ). If initial amounts of chlorophyll are 1 to $2 \mu \mathrm{g} \mathrm{cm}^{-2}$ (or 10 to $20 \mathrm{mg} \mathrm{m}^{-2}$ ), this translates to about 0.2 to $0.4 \%$ of the chlorophyll in 20 min or 3.6 to $7.2 \%$ during a $6 \mathrm{~h}$ high tide. As a maximal estimate, during low tide in small rockpools, about 2 to $4 \%$ of the amounts of chlorophyll present would be removed per $20 \mathrm{~min}$ $\left(245 \times 0.9 \times 1.92=423 \mu \mathrm{g}\right.$ chlorophyll $\left.\mathrm{m}^{-2}\right)$, or 36 to $72 \%$ during a $6 \mathrm{~h}$ low tide.

There are several explanations for why grazing by starfish (and other consumers of micro-algae) does not 
cause amounts of micro-algae measured on the shore to be smaller than observed. As noted by Underwood (1984b), the micro-flora grow and also recruit from the water column, replenishing the amounts grazed. In addition, grazing by Patiriella exigua on micro-algae growing on natural rocky substrata may be less than observed in our study. On rocky shores, micro-algae can grow over long periods of time, either endo- or epilithically, because the sandstone is porous. We have, for example, measured chlorophyll at depths of $5 \mathrm{~mm}$ in sandstone (authors' unpubl. data). On experimental slabs, micro-algae were probably only epilithic because of the short time over which they developed. Eversion of the stomach and extra-cellular digestion by $P$. exigua only removes food from the surface (Anderson 1959, Branch \& Branch 1980, Jangoux 1982), and endolithic algae are not accessible. Second, micro-algae on experimental slabs may have differed from those growing on natural rocky surfaces and, therefore, may have been more rapidly consumed. Variations in structure and topography of rocky surfaces can influence grazing (e.g. Creese 1982); starfish may be less efficient on naturally rough or rugose surfaces than on the smooth surfaces of experimental slabs. Grazing was also measured in cages where incident light and rates of water flow were probably less than under natural conditions. Procedural controls for artifactual effects of cages on grazing were not feasible, because starfish would escape from the usual controls for cages (e.g. roof only, fence only). Grazing marks in the micro-algae were, however, often observed on natural substrata, regardless of any differences in endolithic algae, topography, or assemblages of micro-algae.

Here, removal of chlorophyll by Patiriella exigua was measured in the absence of other species. Interactions such as competition with other species (e.g. Cellana tramoserica; Branch \& Branch 1980, Arrontes \& Underwood 1991) may decrease efficiency, duration, and/or frequency of foraging by starfish, so that the proportion of micro-algae removed from natural substrata may be less than we observed experimentally. Nevertheless, $P$. exigua clearly has the capability to remove a substantial proportion of available microalgal food. No recruitment of grazers or macro-algae was observed on the upper surfaces of grazed or ungrazed slabs during the experiment.

Grazing marks persisted in the field for up to $4 \mathrm{wk}$. Amounts of chlorophyll on slabs were still significantly different $10 \mathrm{~d}$ after grazing had ceased, but did not differ after $28 \mathrm{~d}$. Tests of interval hypotheses also showed that amounts of chlorophyll recovering in grazing marks were not biologically equivalent to amounts in ungrazed areas until 28 d after grazing ceased.

The spectral measures of micro-algae that grew in previously grazed areas were not different from those in ungrazed areas. Thus, grazing by starfish probably did not differentially remove some types of microalgae, which is done by some intertidal grazers, such as acmaeid limpets (Nicotri 1977), nor did it cause growth of micro-algae different from those in ungrazed areas. The originally observed patches of cyanobacteria, similar in size to grazing marks, seem to be caused by processes unrelated to grazing by starfish. It is, however, possible that experimental conditions or insufficient time during the experiment did not allow such patches to develop.

These rocky intertidal shores are known to be overgrazed (i.e. there is insufficient food for the grazers present), thereby causing strong inter- and intraspecific competition among grazers (Underwood 1978, 1984a, Creese \& Underwood 1982), particularly during summer. Recovery of micro-algae (in the absence of continued grazing) occurred over 2 to $4 \mathrm{wk}$, but uninterrupted grazing is likely to cause longer term spatial heterogeneity in micro-algae. Such patchiness can influence small-scale distributions of grazers and the settlement and recruitment of macro-algae and sessile animals. Patiriella exigua is not a good competitor for micro-algal resources (Branch \& Branch 1980, Arrontes \& Underwood 1991), and, until now, the potential for grazing by starfish to remove large amounts of epilithic chlorophyll has not been recognised as contributing to overgrazing of micro-algae. This was largely because no techniques were available to measure amounts of micro-algae at the small scales necessary to analyse such grazing. We have demonstrated that $P$. exigua occur in large numbers, with the potential to graze large amounts of chlorophyll, causing spatial heterogeneity in the amounts of chlorophyll that can persist for weeks. Grazing by starfish may be more ecologically important than previously considered, and the consequences for other intertidal grazers on local rocky shores will need to be unravelled.

Acknowledgements. This study was supported by funds from the Australian Research Council through the Centre for Research on Ecological Impacts of Coastal Cities and ARC Discovery Projects to A.J.U. We thank Paul Devlin and Mark Ellis for their assistance in the field. This work conforms to the policies on ethics in research of the University of Sydney and of the Centre for Research on Ecological Impacts of Coastal Cities.

\section{LITERATURE CITED}

Anderson JM (1959) Studies on the cardiac stomach of a starfish, Patiria miniata (Brandt). Biol Bull 117:185-201

Arrontes J, Underwood AJ (1991) Experimental studies on some aspects of the feeding ecology of the intertidal starfish Patiriella exigua. J Exp Mar Biol Ecol 148:255-269

Barnes H, Powell HT (1950) The development, general morphology and subsequent elimination of barnacle popula- 
tions, Balanus crenatus and Balanus balanoides, after a heavy initial set. J Anim Ecol 32:107-127

Branch GM, Branch ML (1980) Competition between Cellana tramoserica (Sowerby) (Gastropoda) and Patiriella exigua (Lamarck) (Asteroidea), and their influence on algal standing stocks. J Exp Mar Biol Ecol 48:35-49

$>$ Castenholz R (1961) Effect of grazing on marine littoral diatom populations. Ecology 42:783-794

Chesher RH (1969) Destruction of Pacific corals by sea star Acanthaster planci. Science 165:280-283

$>$ Creed RP (1994) Direct and indirect effects of crayfish grazing in a stream community. Ecology 75:2091-2103

> Creese RG (1982) Distribution and abundance of the acmaeid limpet, Patelloida latistrigata, and its interaction with barnacles. Oecologia 52:85-96

> Creese RG, Underwood AJ (1982) Analysis of inter- and intraspecific competition amongst limpets with different methods of feeding. Oecologia 53:337-346

Crump RG, Emson RH (1978) Some aspects of populationdynamics of Asterina gibbosa (Asteroidea). J Mar Biol Assoc UK 58:451-466

> Dayton PK (1971) Competition, disturbance, and community organization-provision and subsequent utilization of space in a rocky intertidal community. Ecol Monogr 41:351-389

Doncaster CP (2001) Healthy wrinkles for population dynamics: unevenly spread resources can support more users. J Anim Ecol 70:91-100

$>$ Duggins DO (1983) Starfish predation and the creation of mosaic patterns in a kelp-dominated community. Ecology 64:1610-1619

> Fletcher WJ (1987) Interactions among subtidal Australian sea-urchins, gastropods, and algae-effects of experimental removals. Ecol Monogr 57:89-109

Fletcher WJ, Underwood AJ (1987) Interspecific competition among subtidal limpets: effects of substratum heterogeneity. Ecology 68:387-400

Fransen B, de Kroon H, Berendse F (2001) Soil nutrient heterogeneity alters competition between two perennial grass species. Ecology 82:2534-2546

> Haven SB (1973) Competition for food between intertidal gastropods Acmaea scabra and Acmaea digitalis. Ecology 54:143-151

Hawkins SJ, Hartnoll RG (1983) Grazing of intertidal algae by marine invertebrates. Oceanogr Mar Biol Annu Rev 21: 195-285

> Hixon MA, Brostoff WN (1996) Succession and herbivory: effects of differential fish grazing on Hawaiian coral-reef algae. Ecol Monogr 66:67-90

> Hixon MA, Menge BA (1991) Species-diversity-prey refuges modify the interactive effects of predation and competition. Theor Popul Biol 39:178-200

Hobbs NT (1996) Modification of ecosystems by ungulates. J Wildl Manag 60:695-713

Huffaker CB (1958) Experimental studies on predation: dispersion factors and predator-prey oscillations. Hilgardia 27:343-383

Jangoux M (1982) Food and feeding mechanisms: Asteroidea. In: Jangoux M, Lawrence JM (eds) Echinoderm nutrition. A.A. Balkema, Rotterdam, p 117-159

> Johnson MP, Burrows MT, Hartnoll RG, Hawkins SJ (1997) Spatial structure on moderately exposed rocky shores: patch scales and the interactions between limpets and algae. Mar Ecol Prog Ser 160:209-215

Keough MJ, Raimondi PT (1995) Responses of settling invertebrate larvae to bioorganic films: effects of different types of films. J Exp Mar Biol Ecol 185:235-253
Keough MJ, Raimondi PT (1996) Responses of settling invertebrate larvae to bioorganic films: effects of large-scale variation in films. J Exp Mar Biol Ecol 207:59-78

Lampert W, Fleckner W, Rai H, Taylor BE (1986) Phytoplankton control by grazing zooplankton - a study on the spring clear-water phase. Limnol Oceanogr 31:478-490

Lawrence JM (1975) On the relationships between marine plants and sea urchins. Oceanogr Mar Biol Annu Rev 13:213-286

Laxton JH (1974) A preliminary study of biology and ecology of the blue starfish Linckia laevigata (L.) on the Australian Great Barrier Reef and an interpretation of its role in the coral reef ecosystem. Biol J Linn Soc 6:47-64

Macarthur R, Macarthur JW (1961) On bird species-diversity. Ecology 42:594-598

Murdoch WW (1977) Stabilizing effects of spatial heterogeneity in predator-prey systems. Theor Popul Biol 11:252-273

> Murphy RJ, Underwood AJ (2006) Novel use of digital colourinfrared imagery to test hypotheses about grazing by intertidal herbivorous gastropods. J Exp Mar Biol Ecol 330:437-447

Murphy RJ, Underwood AJ, Pinkerton MH, Range P (2005a) Field spectrometry: new methods to investigate epilithic micro-algae on rocky shores. J Exp Mar Biol Ecol 325: $111-124$

Murphy RJ, Tolhurst TJ, Chapman MG, Underwood AJ (2005b) Estimation of surface chlorophyll-a on an emersed mudflat using field spectrometry: accuracy of ratios and derivative-based approaches. Int $\mathrm{J}$ Remote Sens 26: 1835-1859

> Murphy RJ, Underwood AJ, Pinkerton MH (2006) Quantitative imaging to measure photosynthetic biomass on an intertidal rock-platform. Mar Ecol Prog Ser 312:45-55

> Nicotri ME (1977) Grazing effects of four marine intertidal herbivores on microflora. Ecology 58:1020-1032

Ogden JC, Brown RA, Salesky N (1973) Grazing by echinoid Diadema antillarum Philippi-formation of halos around West-Indian patch reefs. Science 182:715-717

> Paine RT (1974) Intertidal community structure-experimental studies on relationships between a dominant competitor and its principal predator. Oecologia 15:93-120

Paine RT, Vadas RL (1969) Effects of grazing by sea urchins, Strongylocentrotus spp., on benthic algal populations. Limnol Oceanogr 14:710-719

Sammarco PW, Levinton JS, Ogden JC (1974) Grazing and control of coral-reef community structure by Diadema antillarum Philippi (Echinodermata-Echinoidea)- preliminary study. J Mar Res 32:47-53

Savitzky A, Golay MJE (1964) Smoothing and differentiation of data by simplified least squares procedures. Anal Chem 36:1627-1639

Schuirmann DJ (1987) A comparison of the two one-sided tests procedure and the power approach for assessing the equivalence of average bioavailability. J Pharmacokinet Pharmacodyn 15:657-680

Sloan NA (1980) Aspects of the feeding biology of asteroids. Oceanogr Mar Biol Annu Rev 18:57-124

Stafford R, Davies MS (2005) Spatial patchiness of epilithic biofilm caused by refuge-inhabiting high shore gastropods. Hydrobiologia 545:279-287

Stevenson JP (1992) A possible modification of the distribution of the intertidal seastar Patiriella exigua (Lamarck) (Echinodermata, Asteroidea) by Patiriella calcar (Lamarck). J Exp Mar Biol Ecol 155:41-54

Underwood AJ (1978) An experimental evaluation of competition between three species of intertidal prosobranch gastropods. Oecologia 33:185-208 
Underwood AJ (1980) The effects of grazing by gastropods and physical factors on the upper limits of distribution of intertidal macroalgae. Oecologia 46:201-213

Underwood AJ (1981) Structure of a rocky intertidal community in New South Wales: patterns of vertical distribution and seasonal changes. J Exp Mar Biol Ecol 51:57-85

Underwood AJ (1984a) Vertical and seasonal patterns in competition for microalgae between intertidal gastropods. Oecologia 64:211-222

Underwood AJ (1984b) The vertical distribution and seasonal abundance of intertidal microalgae on a rocky shore in New South Wales. J Exp Mar Biol Ecol 78:199-220

Underwood AJ (1984c) Microalgal food and the growth of the intertidal gastropods Nerita atramentosa Reeve and Bembicium nanum (Lamarck) at four heights on a shore. J Exp Mar Biol Ecol 79:277-291

Underwood AJ (1985) Physical factors and biological interactions: the necessity and nature of ecological experiments. In: Moore PG, Seed R (eds) The ecology of rocky coasts.

Editorial responsibility: Hans Heinrich Janssen, Oldendorf/Luhe, Germany
Hodder and Stoughton, London, p 171-190

Underwood AJ, Jernakoff P (1981) Effects of interactions between algae and grazing gastropods on the structure of a low-shore intertidal algal community. Oecologia 48: 221-233

- Underwood AJ, Murphy RJ (2008) Unexpected patterns in facilitatory grazing of intertidal microalgae revealed by novel quantitative imaging. Mar Ecol Prog Ser 358:85-94

> Underwood AJ, Denley EJ, Moran MJ (1983) Experimental analyses of the structure and dynamics of mid-shore rocky intertidal communities in New South Wales. Oecologia $56: 202-219$

Valentine JF, Heck KL (1991) The role of sea urchin grazing in regulating subtropical seagrass meadows-evidence from field manipulations in the northern Gulf of Mexico. J Exp Mar Biol Ecol 154:215-230

Wieczorek SK, Todd CD (1998) Inhibition and facilitation of settlement of epifaunal marine invertebrate larvae by microbial biofilm cues. Biofouling 12:81-118

Submitted: July 23, 2008; Accepted: October 29, 2008

Proofs received from author(s): February 2, 2009 